This is the final peer-reviewed accepted manuscript of:

Giulia Ramazzotti, Roberta Fiume, Francesca Chiarini, Gabriele Campana, Stefano Ratti, Anna Maria Billi, Lucia Manzoli, Matilde Y. Follo, Pann-Gill Suh, James McCubrey, Lucio Cocco, Irene Faenza,

Phospholipase C- $\beta 1$ interacts with cyclin E in adipose- derived stem cells osteogenic differentiation,

Advances in Biological Regulation, Volume 71, 2019, Pages 1-9, ISSN 2212-4926

The final published version is available online at: $h$ ttp://dx.doi.org/10.1016/.jbior.2018.11.001

Rights / License: CCBYNCND

The terms and conditions for the reuse of this version of the manuscript are specified in the publishing policy. For all terms of use and more information see the publisher's website.

This item was downloaded from IRIS Università di Bologna (https://cris.unibo.it/)

When citing, please refer to the published version. 


\title{
Phospholipase C- $\beta 1$ interacts with cyclin E in adipose- derived stem cells osteogenic differentiation
}

\author{
Giulia Ramazzotti ${ }^{\mathrm{a}}$, Roberta Fiume ${ }^{\mathrm{a}}$, Francesca Chiarini ${ }^{\mathrm{b}}$, Gabriele Campana ${ }^{\mathrm{c}}$, Stefano Ratti ${ }^{\mathrm{a}}$, \\ Anna Maria Billi ${ }^{\mathrm{a}}$, Lucia Manzoli ${ }^{\mathrm{a}}$, Matilde Y. Follo ${ }^{\mathrm{a}}$, Pann-Gill Suh ${ }^{\mathrm{d}}$, James McCubrey ${ }^{\mathrm{e}}$, \\ Lucio Cocco ${ }^{\text {a }}$, Irene Faenza ${ }^{\mathrm{a}, *}$
}

\footnotetext{
a Section of Human Anatomy, Department of Biomedical and Neuromotor Sciences, University of Bologna, via Irnerio 48, 40126, Bologna, Italy

${ }^{\mathrm{b}}$ Institute of Molecular Genetics - Bologna Unit, c/o Istituto Ortopedico Rizzoli, via di Barbiano 1-10, 40138, Bologna, Italy

${ }^{\mathrm{c}}$ Department of Pharmacy and Biotechnology, University of Bologna, via Irnerio 48, 40126, Bologna, Italy

${ }^{\mathrm{d}}$ Ulsan National Institute of Science and Technology (UNIST), Ulsan Metropolitan City, Republic of Korea

e East Carolina University, Greenville, NC, USA
}

\section{A R T I C L E INFO}

\section{Keywords}

PLC- $\beta 1$

Cyclin E

Adipose derived stem cells

Stem cell differentiation

Osteogenesis

\begin{abstract}
A B S T R A C T
Adipose-derived stem cells (ADSCs) are multipotent mesenchymal stem cells that have the ability to differentiate into several cell types, including chondrocytes, osteoblasts, adipocytes, and neural cells. Given their easy accessibility and abundance, they became an attractive source of mesenchymal stem cells, as well as candidates for developing new treatments for reconstructive medicine and tissue engineering. Our study identifies a new signaling pathway that promotes ADSCs osteogenic differentiation and links the lipid signaling enzyme phospholipase C (PLC)- $\beta 1$ to the expression of the cell cycle protein cyclin E. During osteogenic differentiation PLC- $\beta 1$ expression varies concomitantly with cyclin E expression and we show that the two proteins interact. These findings contribute to clarify the pathways involved in osteogenic differentiation and provide evidence to develop therapeutic strategies for bone regeneration.
\end{abstract}

\section{Introduction}

Adipose-derived stem cells (ADSCs) are multipotent mesenchymal cells, that show the ability of self-renewal and that can differentiate into cells of mesodermal lineages, like adipocytes, chondrocytes, myocytes, and osteoblasts, as well as into cells of ectodermal lineages, like neurocytes (Bunnell et al., 2008; Zuk et al., 2001). Given their differentiation ability, ADSCs represent important therapeutic candidates for a wide range of diseases, such as stroke, inflammatory bowel disease, liver failure, cutaneous lesions and osteoarthritis, and are key players for regenerative medicine (Bateman et al., 2018; Zimmerlin et al., 2013). Moreover, ADSCs are easily accessible since they can be isolated from the stromal vascular fraction of adipose tissue collected through liposuction (Kern et al., 2006) and are relatively more abundant than bone marrow mesenchymal stem cells (Hurley et al., 2018). Thanks to their ability to differentiate into osteoblasts, ADSCs may represent an important therapeutic option for the treatment of bone defects and metabolic diseases (Sancricca et al., 2010). Therefore, it is important to understand the signaling pathways involved in regulating ADSCs' osteogenic differentiation.

\footnotetext{
* Corresponding author. DIBINEM, Sezione Anatomia Umana, via Irnerio 48, 40126, Bologna, Italy.

Email address: Irene.faenza2@unibo.it (I. Faenza)
} 
Osteogenic differentiation is a complex process that requires the action and integration of several signaling pathways and it is still not completely elucidated. It involves transforming growth factor $\beta$ (TGF- $\beta$ )/bone morphogenic (BMP), Wnt, Hedgehog, Notch, and fibroblast growth factor (FGF) pathways (Chen et al., 2016). The TGF- $\beta$ signaling pathway can trigger both osteogenic and adipogenic differentiation of mesenchymal stem cells depending on cytokines concentration in their microenvironment (Kang et al., 2009; Wu et al., 2016). Several studies indicate that Wnt signaling promotes osteogenic differentiation by causing $\beta$-catenin translocation to the nucleus (Clevers et al., 2014; Park et al., 2015; Yuan et al., 2016). Hedgehog pathway induces as well osteogenic differentiation and it can cross-talk with BMP pathway (James et al., 2012; Kim et al., 2010; LI et al., 2015; Spinella-Jaegle et al., 2001). On the other hand, Notch signaling has a dual role: it can inhibit osteogenic differentiation by interfering with Wnt signaling or it can be a positive regulator by promoting BMP2 pathway (Deng et al., 2008; Shimizu et al., 2011). Finally, FGFs regulate osteogenic differentiation by interacting with Wnt and TGF- $\beta$ pathways (Eswarakumar et al., 2005; Jackson et al., 2006; Kratchmarova et al., 2005; Woei Ng et al., 2007).

Several studies have demonstrated that the lipid-signaling enzyme phospholipase C- $\beta 1$ (PLC- $\beta 1$ ) plays a fundamental role in murine mesenchymal cells differentiation. PLC- $\beta 1$ hydrolyses the signaling lipid phosphatidylinositol 4,5-bisphosphate (PI-4,5P $\left.{ }_{2}\right)$ to produce $2 \mathrm{~s}$ messengers: inositol 1,4,5-trisphosphate $\left(\mathrm{IP}_{3}\right)$ and diacylglycerol (DAG), that in turn modulate many downstream effectors (Rhee, 2001). PLC- $\beta 1$-dependent signaling regulates a variety of cellular processes, like proliferation, differentiation, metabolism and membrane trafficking, and its deregulation may lead to several pathologies, like chronic inflammation, atherosclerosis, metabolic syndromes, and cancer (Faenza et al., 2005; Follo et al., 2015; Poli et al., 2013; Wymann and Schneiter, 2008). During 3T3-L1 adipogenic differentiation, PLC- $\beta 1$ is required for the early stage round of mitosis, called mitotic clonal expansion, and at later stages for maintaining the differentiation state. Moreover, PLC- $\beta 1$ is required for the regulation of the cell cycle proteins cyclin D3 and cdk4, involved in the differentiation process (O'Carroll et al., 2009). During myogenic differentiation of the murine myoblast cell line C2C12, PLC- $\beta 1$ expression increases at mRNA and protein level and its expression is required for the differentiation process to take place (Faenza et al., 2003; Ramazzotti et al., 2008). Furthermore, its signaling pathway determines the activation mediated by c-jun of a specific cyclin

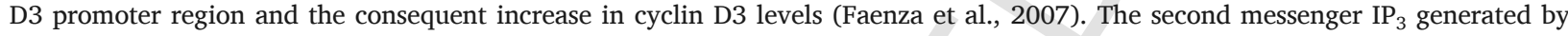
PLC- $\beta 1$ enzymatic activity is in turn the substrate of Inositol Phosphate Multikinase (IPMK), that produces higher phosphorylate inositol species. The consequent increase in $\mathrm{IP}_{5}$ levels determines the nuclear translocation of $\beta$-catenin, resulting in cyclin D3 promoter activation through c-jun (Ramazzotti et al., 2016a,b).

C2C12 cell line represents a well-established model also for osteogenic transdifferentiation, following to BMP-2 administration (Katagiri et al., 1994). During osteogenic differentiation, PLC- $\beta 1$ expression increases and its silencing slows down the differentiation process. Cyclin D3 appears not to be involved in osteogenic differentiation in response to PLC- $\beta 1$ signaling pathway, since alteration of PLC- $\beta 1$ expression does not affect cyclin D3 levels. Moreover, miR-214, which inhibits C2C12 osteogenic differentiation by targeting the transcription factor Osterix (Shi et al., 2013), was shown to down-regulate also PLC- $\beta 1$ expression (G. Ramazzotti et al., 2016a,b).

Taken together these studies suggest that PLC- $\beta 1$ could be involved also in human mesenchymal stem cell differentiation, therefore we decided to investigate its role in human ADSCs osteogenic differentiation hypothesizing that targeting this molecule could be important for normalizing the differentiation processes in human diseases.

\section{Material and methods}

\subsection{Cell culture, differentiation and retroviral transduction}

ADSCs were purchased from ThermoFisher Scientific and cultured in Complete MesenPro RS medium (Gibco), in $37^{\circ} \mathrm{C}$ incubator with 5\% CO2, as described in the manufacturer's protocol. Human embryonic kidney (HEK 293) cells were grown in DMEM supplemented with $10 \%$ fetal bovine serum (Sigma- Aldrich).

ADSCs were differentiated toward the osteogenic lineage by seeding $5 \times 10^{3}$ cells $/ \mathrm{cm}^{2}$ in a T75 flask and replacing the culture medium after 2 days with Complete STEMPRO Osteogenesis Differentiation Medium (Gibco). After 14 and 21 days, cells were stained with Alizarin Red $\mathrm{S}$ in order to detect the calcium deposits in the culture.

For adipogenic differentiation, $1 \times 10^{4}$ cells $/ \mathrm{cm}^{2}$ were seeded in a T75 flask, and growth medium was replaced after 2 days with Complete Adipogenesis Differentiation Medium (Gibco). After 14 and 21 days, cultures were processed for Oil Red O staining, to stain lipids.

eEF1 $\alpha$ and pLKO.1 retroviral vectors used for retroviral transduction were a generous gift from Dr. Nullin Divecha. The plasmid code respectively for human Phospholipase C- $\beta 1$ and for its shRNA. In order to produce the lentiviral particles, the day before transfection HEK 293 cells were seeded at $70 \%$ confluence in a 6-well plate. After $24 \mathrm{~h}$, the cells were transfected using a mixture of $1.14 \mu \mathrm{g}$ of target DNA, $570 \mathrm{ng}$ of gag-pol coding vector, and $280 \mathrm{ng}$ of vsv-g coding vector, and $6 \mu \mathrm{l}$ of PEI in $100 \mu \mathrm{l}$ of OptiMEM (Gibco). The mixture was added drop-wise to the cells and incubated overnight at $37^{\circ} \mathrm{C}$. Then, the overnight culture medium was replaced with fresh DMEM medium supplemented with $5 \%$ heat-inactivated fetal bovine serum and penicillin-streptomycin. The lentivirus-containing medium was collected 24 and $48 \mathrm{~h}$ after the transfection and filtered through a $0.45 \mathrm{~mm}$ cellulose acetate filter. For the transduction, $1.8 \times 10^{5}$ ADSCs were plated per well in a 6-well plate the day before. On the day of the infection, the growth medium was replaced with the lentivirus-containing medium supplemented with $10 \mu \mathrm{l}$ polybrene solution $(0.5 \mathrm{mg} / \mathrm{ml})$ and the plates were centrifuged for $30 \mathrm{~min}$ at $2200 \mathrm{rpm}$. Cells were returned to incubator and selected with $1 \mu \mathrm{g} / \mathrm{ml}$ puromycin $48 \mathrm{~h}$ after infection. 


\subsection{RNA extraction, retrotranscription and real-time PCR}

Total RNA was extracted from growing and differentiating ADSC cells, using RNeasy mini kit (Qiagen). RNA was quantified using a Nanodrop spectrophotometer and cDNA was synthesized starting from $2 \mu \mathrm{g}$ of total RNA using $0.5 \mu \mathrm{g}$ of oligo (dT) 18 primers, 20 U RiboLock ${ }^{\mathrm{TM}}$ RNase Inhibitor, $1 \mathrm{mM}$ dNTP mix and RevertAid H Minus Reverse Transcriptase (ThermoFisher). The reactions were incubated following the manufacture's instruction.

Gene expression was determined by using a probe-based real-time PCR method. We used FastStart Universal Probe Master (Roche) and the following validated assays: PLC- $\beta 1$ Hs.PT.58.24665550, ALP Hs.PT.56a.40555206, cyclin D3 Hs.PT.56a.3707837, GAPDH Hs.PT.39a.22214836 (IDT); cyclin B1 Hs01030099_m1, and cyclin E Hs01025536_m1 (ThermoFisher).

The reactions were performed using the ABI PRISM 7300 real-time PCR instrument (Applied Biosystems) and the samples were analyzed in triplicate. Gene expression was determined by using relative quantification and the $\Delta \Delta \mathrm{Ct}$ method. The results of different sets of experiments were statistically analyzed by using GraphPad Prism version 3.02.

\subsection{Flow cytometry and cell cycle analysis}

In order to assess viral transduction efficiency, ADSCs were transduced with GFP encoding retrovirus and cells were tested for GFP expression $48 \mathrm{~h}$ after transduction. The fraction of GFP positive cells was measured by FACS analysis.

For cell cycle analysis, $5 \times 10^{5}$ cells were collected by centrifugation and washed in PBS twice. In order to fix and permeabilize cells, the pellets were resuspended in ice-cold $70 \%$ ethanol and kept overnight at $-20^{\circ} \mathrm{C}$. Fixed cells were washed in PBS twice and resuspended in $400 \mu \mathrm{l} \mathrm{PBS}$ containing $40 \mu \mathrm{g} / \mathrm{ml}$ propidium iodide and $100 \mu \mathrm{g} / \mathrm{ml}$ RNase A. The samples were incubated for $30 \mathrm{~min}$ at room temperature in the dark, and then FACS analysis was performed. For each analysis, at least 10,000 events were recorded.

Analyses were performed on a FC500 flow cytometer (Beckman Coulter) with the appropriate software (CXP, Beckman Coulter).

\subsection{Western blot}

Cells at different time points were lysed in M-PER extraction reagent supplemented with Halt protease inhibitor cocktail (ThermoFisher), following the manufacturer's instructions. Cell suspension was sonicated prior to the centrifugation step. Whole-cell lysates were quantified with the BCA Protein Assay (Biorad). Fifty $\mu \mathrm{g}$ of whole-cell lysates were separated on Bolt 4-12\% polyacrylamide- $0.1 \%$ SDS gels (ThermoFisher), transferred to nitrocellulose membranes, proved with specific antibodies, and detected with horseradish peroxidase-conjugated secondary antibody. The immunoreactive bands were visualized using an ECL enhanced chemiluminescence system (ThermoFisher) and visualized in a Kodak digital image station 2000R.

The expression of specific proteins was tested by using the following antibodies: anti-PLC- $\beta 1$ (sc-9050) and anti-Osterix (sc-393325) antibodies purchased from Santa Cruz Biotechnology, anti-Cyclin D3 (\#2936) and anti-Cyclin E (\#20808) antibodies from Cell Signaling Technology, anti- $\beta$ tubulin antibody (T7816) purchased from Sigma-Aldrich.

\subsection{Co-immunoprecipitation}

Cells were lysed at $4^{\circ} \mathrm{C}$ for $30 \mathrm{~min}$ in RIPA buffer supplemented with Halt protease inhibitor cocktail (ThermoFisher). $500 \mu \mathrm{g}$ of cell lysate were incubated overnight at $4^{\circ} \mathrm{C}$ with $2 \mu \mathrm{g}$ of anti-PLC- $\beta 1$ antibody (sc-5291, Santa Cruz Biotechnology) followed by $1 \mathrm{~h}$ incubation with $20 \mu \mathrm{l}$ of protein A/G plus-agarose (Santa Cruz Biotechnology) at $4^{\circ} \mathrm{C}$. After 4 washing steps, samples were resolved on Bolt 4-12\% gel polyacrylamide (ThermoFisher) following the Western blot protocol.

\section{Results}

\subsection{Pluripotency of ADSCs}

In order to test ADSCs' ability to differentiate towards different lineages, cells were stimulated to differentiate into osteocytes and adipocytes and analyzed after 14 and 21 days (Fig. 1). Alizarin Red S staining shows the presence of calcium deposits in the culture and the comparison of the 14-days sample to the 21-days sample indicates an increase in extracellular matrix deposits over time. Moreover, Oil Red O staining, that detects neutral lipids in lipid droplets, shows an increase in cytosolic lipid droplets in the samples over time. Both these staining experiments demonstrate the pluripotency of ADSCs.

\subsection{PLC- $\beta 1$ expression in osteogenic differentiation}

In order to understand if PLC- $\beta 1$ expression varies during osteogenic differentiation, we tested samples at different time points, that is after 7, 14, and 21 days of differentiation. Fig. 2 A shows that PLC- $\beta 1$ expression is high in growing cells, it decreases during the first two weeks of differentiation and afterwards it displays a marked increase. Alkaline phosphatase (ALP) was used as a marker of osteogenic differentiation and it increases over time. The data collected by mRNA analysis were subsequently confirmed at protein level (Fig. 2 B). Western blot analysis indicates that PLC- $\beta 1$ expression is at first reduced until day 14 of differentiation, and 
B

A

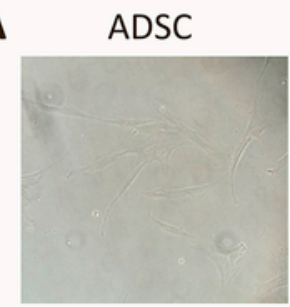

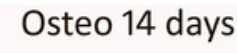
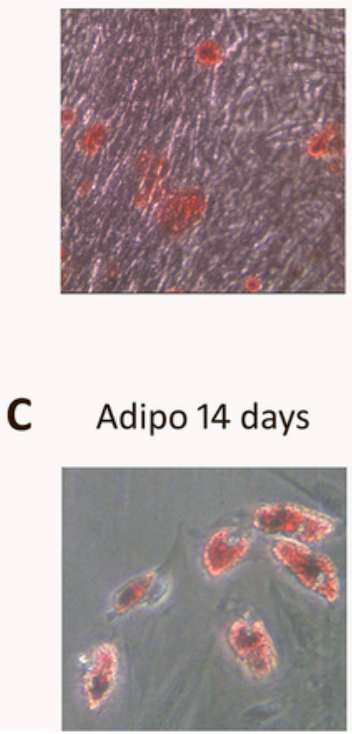

Osteo 21 days

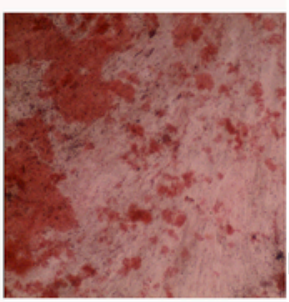

Adipo 21 days

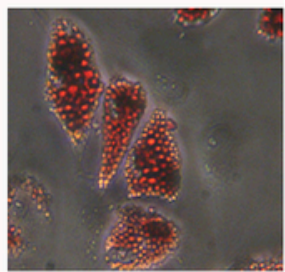

Fig. 1. ADSCs pluripotency: differentiation to osteoblasts and adipocytes. (A) ADSCs cultured in growth medium; (B) ADSCs cultured in osteogenic medium for 14 and 21 days and stained with Alizarin Red; (C) ADSCs cultured in adipogenic medium for 14 and 21 days and stained with Oil Red O. Representative view using bright field microscopy. (For interpretation of the references to colour in this figure legend, the reader is referred to the Web version of this article.)

A

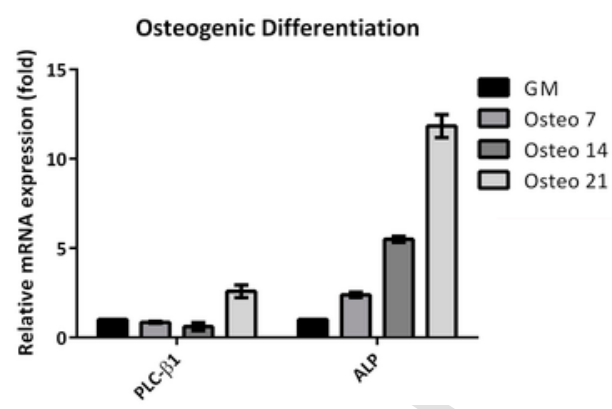

B

GM $\quad 07 \quad 014 \quad 021$

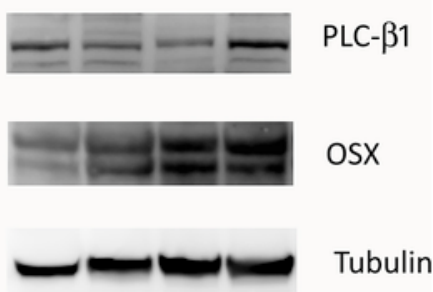

Fig. 2. PLC- $\beta 1$ expression during ADSCs osteogenic differentiation. (A) PLC- $\beta 1$ and phosphatase alkaline (ALP) expression was evaluated by real-time PCR in ADSCs kept in growing medium (GM) and after 7, 14 and 21 day-culture in osteogenic differentiation medium (respectively O7, O14 and O21). (B) PLC- $\beta 1$ and Osterix (OSX) expression was evaluated by Western blot in lysates form growing (GM) and differentiating ADSCs after 7, 14 and 21 day-culture in osteogenic differentiation medium (respectively O7, O14 and O21). Tubulin was used as loading control. Data are representative of five independent sets of experiments.

then increases at day 21. Osteogenic differentiation was confirmed by the evaluation of Osterix (OSX) expression. Therefore, these data suggest that PLC- $\beta 1$ may be involved in the later stages of the differentiation process.

\subsection{PLC- $\beta 1$ overexpression promotes osteogenic differentiation}

Next, we investigated the effects of PLC- $\beta 1$ overexpression and silencing on ADSCs osteogenic differentiation. Cells were transduced by retroviral vectors achieving about $85 \%$ transduction efficiency, as assessed by FACS analysis (Fig. 3 A). After puromycin selection, cells were differentiated for 7 days. At light microscope, PLC- $\beta 1$ overexpressing cells (ov- $\beta 1$ ) differ from silenced cells (si- $\beta 1$ ) (Fig. 3 B). PLC- $\beta 1$-transduced cells show a more rod-shaped appearance than mock-transduced cells. Nonetheless, silenced cells show a more polygonal shape compared to scramble-transduced (shx) cells. Both mock- and scramble-transduced cells strongly resemble non-transduced ADSCs in shape in bright field microscopy. Besides, silenced cells could not be grown for longer than 2 weeks because of massive cell death (data not shown). Furthermore, mRNA analysis displays a higher ALP expression in PLC- $\beta 1$ overexpressing cells compared to the control while silenced cells show a marked reduction in ALP expression in comparison with the control sample (Fig. $3 \mathrm{C}$ ). Taken together these data indicate that PLC- $\beta 1$ contributes to the process of osteogenic differentiation. 
A

CTRL

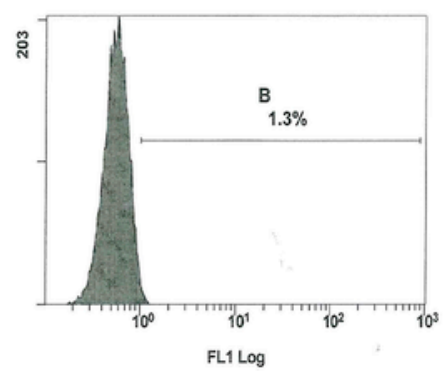

B

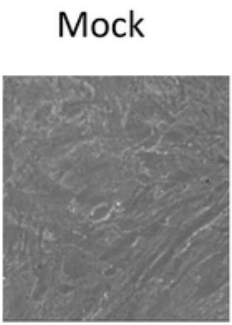

ovPLC- $\beta 1$

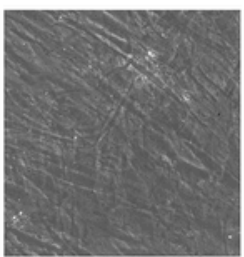

GFP

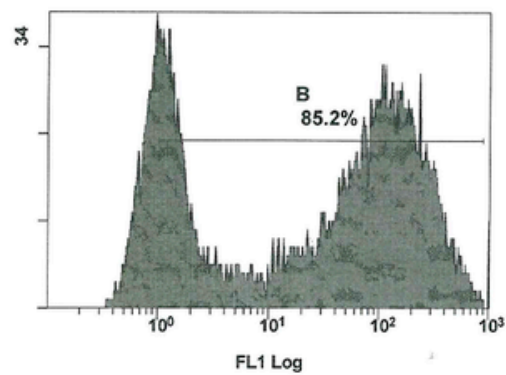

Shx siPLC- $\beta 1$
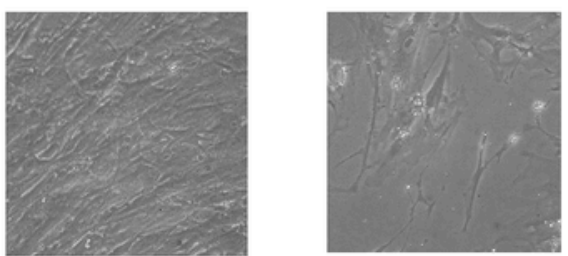

C

\section{Osteogenic Differentiation}

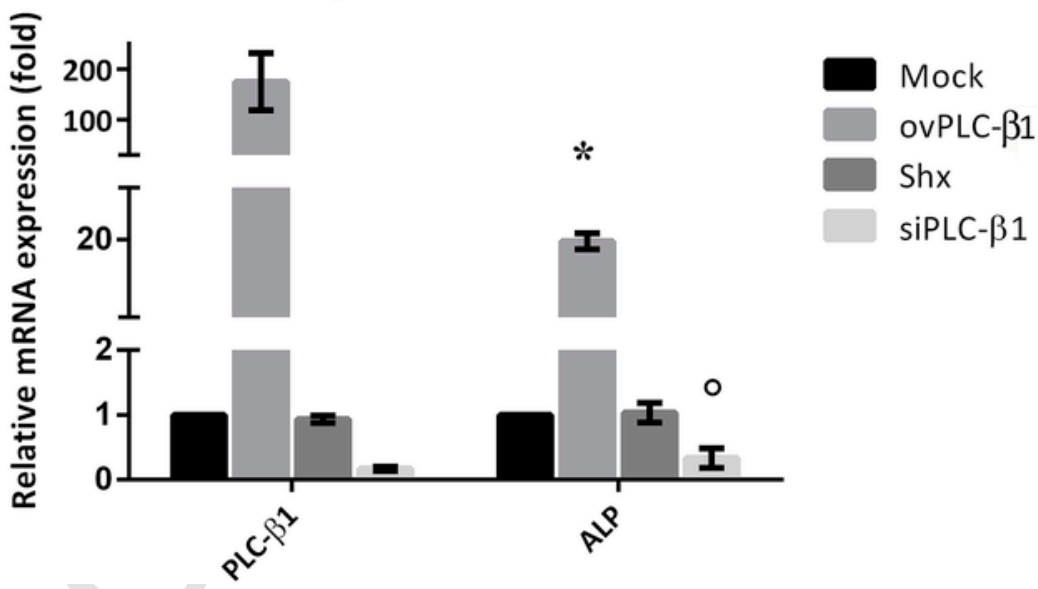

Fig. 3. Effects of PLC- $\beta 1$ modulation on ADSCs osteogenic differentiation. (A) Evaluation of transduction efficiency by FACS analysis; (B) Evaluation of transducted cells morphology under bright field microscopy: mock and shx represent the control samples to PLC- $\beta 1$ overexpressing (ovPLC- $\beta 1$ ) and PLC- $\beta 1$ silenced (siPLC- $\beta 1$ ) cells, respectively; (C) PLC- $\beta 1$ and ALP expression was evaluated by real-time PCR in transduced ADSCs after 7 day-culture in osteogenic differentiation. Data are representative of five independent sets of experiments. ${ }^{*},{ }^{\circ} p<0.05$ vs corresponding control sample.

\subsection{Evaluation of cyclins expression during ADSC osteogenic differentiation}

Since we have previously demonstrated that PLC- $\beta 1$ expression varies with and affects cyclin D3 expression in a different cellular model (Faenza et al., 2007), we investigated the expression of cyclin B1, D3 and E in ADSC osteogenic differentiation. Real-time PCR analysis of ADSCs collected after 7, 14 and 21 days of differentiation shows a gradual decrease of cyclin B1 expression during differ- 
entiation. Cyclin D3 displays an initial limited increase followed by a steady reduction. Meanwhile, cyclin E expression is reduced at first and then markedly increased (Fig. 4 A). Therefore cyclin E expression pattern matches PLC- $\beta 1$ expression during osteogenic differentiation. These data were confirmed by Western blot analysis of sample collected respectively after 7, 14 and 21 days of differentiation (Fig. 4 B). Again PLC- $\beta 1$ and cyclin E expression varies following the same pattern: an initial reduction followed by a marked increase.

The samples were also analyzed for cell cycle distribution. Cell cycle analysis indicates that during the first week of osteogenic differentiation there is a reduction in the G2/M phase population. During the second week of differentiation, we observed still a decrease in G2/M phase but on the third week, we detected an increase in G2/M phase, matching PLC- $\beta 1$ and cyclin E variations in expression.

\subsection{PLC- $\beta 1$ and cyclin E co-immunoprecipitate}

Since PLC- $\beta 1$ and cyclin E trend of expression follows the same pattern during osteogenic differentiation of ADSC, we investigated whether the two proteins co-immunoprecipitate. PLC- $\beta 1$ was immunoprecipitated in samples from ADSCs differentiated for 21 days and Western blot was used to check for cyclin E co-immunoprecipitation. Fig. 5 shows that the two proteins co-immunoprecipitate, therefore they physically interact. Moreover, the binding between PLC- $\beta 1$ and cyclin E becomes more prominent as the differentiation process proceeds, as co-immunoprecipitation in samples differentiated for 14 days is almost undetectable (data not shown).

A

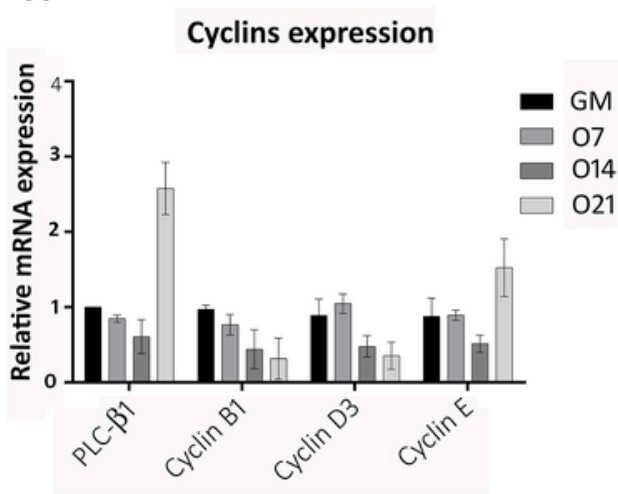

B
GM $\quad 07 \quad 014021$
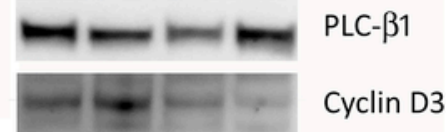

Cyclin E

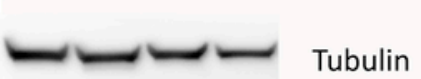

C

GM

07
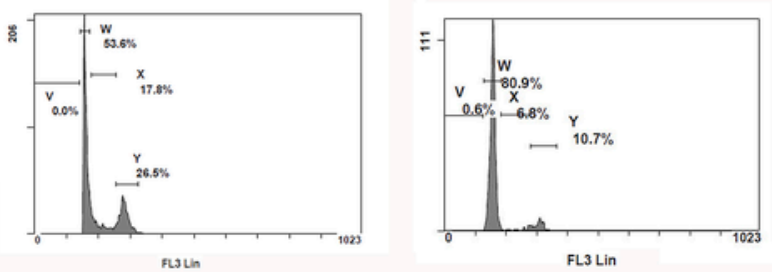

014

021
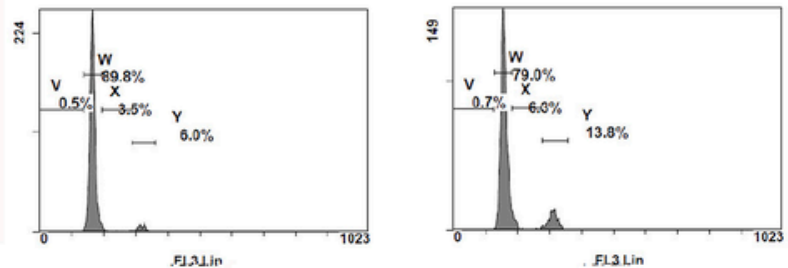

Fig. 4. Cyclins expression during osteogenic differentiation. (A) PLC- $\beta 1$, cyclin B1, cyclin D3 and cyclin E expression was evaluated by real-time PCR in ADSCs kept in growing medium (GM) and after 7, 14 and 21 day-culture in osteogenic differentiation medium (respectively O7, O14 and O21). (B) PLC- $\beta 1$, cyclin D3, and cyclin E expression was evaluated by Western blot in lysates from growing (GM) and differentiating ADSCs after 7, 14 and 21 day-culture in osteogenic differentiation medium (respectively O7, O14 and O21). Tubulin was used as loading control. (C) Cell cycle analysis of growing (GM) and differentiating ADSCs at different time points (7, 14 and 21 day-culture). Data are representative of five independent sets of experiments. 


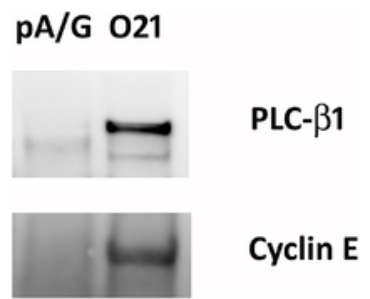

Fig. 5. PLC- $\beta 1$ and cyclin E co-immunoprecipitate. PLC- $\beta 1$ was immunoprecipitated in lysates of ADSCs differentiated for 21 days (O21), and samples were probed with anti-cyclin E antibody. Lysate incubated with protein A/G only was used as negative control (pA/G). Data are representative of three independent sets of experiments.

\section{Discussion}

ADSCs are mesenchymal stem cells that can differentiate into different cell types, including osteoblasts, under specific growth conditions (Pittenger et al., 1999). So far, the molecular mechanisms underlying lineage differentiation have been investigated but are not completely understood yet limiting further development of ADSC-based clinical applications. Therefore, it is critical to gain a better understanding of the molecular mechanisms regulating the osteogenic differentiation of ADSCs. Several studies on cell lines showed that PLC- $\beta 1$ plays a central role in cell differentiation processes, particularly in the muscle-skeletal system. Indeed, both myogenesis and osteogenesis are characterized by a marked increase in PLC- $\beta 1$ expression and these processes are both inhibited by PLC- $\beta 1$ silencing. This suggests that PLC- $\beta 1$ can be involved also in mesenchymal stem cell differentiation, so that targeting this molecule could be crucial for normalizing the differentiation processes in different bone conditions. In a previous study, we demonstrated that osteogenic transdifferentiation of C2C12 cells in response to BMP-2 stimulation is characterized by a marked increase in nuclear PLC- $\beta 1$ expression (Ramazzotti et al., 2016a,b). Moreover, we reported previously that in insulin-stimulated C2C12 myoblasts, PLC- $\beta 1$ expression is increased and is important for the up-regulation of myogenic markers during myogenic differentiation (Faenza et al., 2007). In the present study, we show that PLC- $\beta 1$ is already highly expressed in proliferating ADSCs and that during the early stages of osteogenic differentiation the levels of PLC- $\beta 1$ decrease. These data are in contrast with our previous observations on myogenic differentiation but to some extent, they agree with our study on myotonic dystrophy. Myoblasts obtained from biopsies of patients affected by type 2 myotonic dystrophy are characterized by high levels of expression of PLC- $\beta 1$ during the proliferation phase followed by a strong decrease in the expression of PLC- $\beta 1$ during the differentiation process (Faenza et al., 2012).

Moreover, our data show a transient decrease in PLC- $\beta 1$ expression, followed by an induction after 21 days of differentiation. Several studies on erythropoiesis suggest that PLC- $\beta 1$ promotes cell proliferation by controlling the G1/S transition of the cell cycle and that its down regulation is required for the cells to exit the cell cycle and differentiate (Bavelloni et al., 2014; Faenza et al., 2000; M.Y. Follo et al., 2012a,b; Mongiorgi et al., 2016). Actually, the role of PLC- $\beta 1$ in cell proliferation and differentiation is controversial. Different cellular models, diverse for lineage derivation and species of origin, display different roles for PLC- $\beta 1$ in modulating the proliferation or the differentiation process. In HL-60 human promyelocytic leukaemia cells, PLC- $\beta 1$ activity peaks at late G1 phase and at G2/M transition and it is necessary for cell cycle progression (Lukinovic-Skudar et al., 2005), and in Ba/F3 pro-B-lymphoblastic cells PLC- $\beta 1$ promotes cell proliferation and resistance to cell death (Piazzi et al., 2015). However, in K562 human erythroleukemia cells PLC- $\beta 1$ overexpression determines a prolonged S phase of the cell cycle and a delay in cell proliferation (Poli et al., 2016, 2013). Indeed, PLC- $\beta 1$ expression is reduced during erythroid differentiation of Friend murine erythroleukemia cells and in normal CD34 ${ }^{+}$cells (Cocco et al., 2016; M Y Follo et al., 2012a,b; Ratti et al., 2018). On the other hand, PLC- $\beta 1$ expression increases during myogenic and osteogenic differentiation of C2C12 cells, as already discussed above (Faenza et al., 2004; Ramazzotti et al., 2016a,b, 2017). Finally, in adipogenic differentiation of 3T3-L1 mouse embryonic fibroblasts PLC- $\beta 1$ shows a dual role: its expression increases during the early round of mitosis, the mitotic clonal expansion, and later in order to maintain the differentiation state. The early increase in PLC- $\beta 1$ activity and expression was observed as soon as $5 \mathrm{~min}$ after the stimulus to differentiate and then a second peak was seen after day 2 of differentiation (O'Carroll et al., 2009). Therefore, we propose that PLC- $\beta 1$ might have a dual role also during osteogenic differentiation.

Furthermore, previous observations indicated that the cyclin D3/cdk4 complex is a downstream target of PLC- $\beta 1$ signaling during myogenic differentiation (Faenza et al., 2007, 2004). Here we show that cyclin D3 expression is not increased during ADSC osteogenic differentiation as compared to proliferating cells. Nevertheless, these data are in agreement with previous results indicating that cyclin D3 levels did not increase in response to BMP-2 induced osteogenic differentiation (G. Ramazzotti et al., 2016a,b). Therefore, our study provides more evidences that cyclin D3 has an important role in promoting myogenic differentiation but it is not involved in promoting osteogenic differentiation.

Besides, not only cyclin E displays a constitutively high expression level in proliferating ADSCs but also its expression pattern varies following PLC- $\beta 1$ expression, showing an initial reduction followed by a marked increase. Our results present that the two proteins co-immunoprecipitate hence they physically interact. Cyclin E has already been linked to PLC- $\beta 1$ activity in relation to S-phase progression in Ba/F3 pro-B-lymphoblastic cells after $\mathrm{H}_{2} \mathrm{O}_{2}$ treatment (Piazzi et al., 2015). The authors show that PLC- $\beta 1$ overexpression upregulates cyclin $\mathrm{E}$ expression and promotes cell cycle progression. 


\section{Conclusion}

The emerging feature from our study hints at a new pathway leading to osteogenic differentiation that links PLC- $\beta 1$ signaling to the expression of cyclin E. Further investigations are required to define all the molecular mechanisms underlying PLC- $\beta 1$ signaling in osteogenic differentiation, and to determine if the interaction between PLC- $\beta 1$ and cyclin $\mathrm{E}$ is direct or if it requires mediators yet to be identified.

\section{Conflicts of interest}

No author has an actual or perceived conflict of interest with the contents of this article.

\section{Acknowledgments}

This work was supported by fundamental contribution of Fondazione del Monte di Bologna e Ravenna to I.F., and Funds for Basic Oriented Research (RFO) of the University of Bologna to I.F.

\section{References}

Bateman, M.E., Strong, A.L., Gimble, J.M., Bunnell, B.A., 2018. Using fat to fight disease: a systematic review of non-homologous adipose-derived stromal/stem cell therapies. Stem Cell. https://doi.org/10.1002/stem.2847.

Bavelloni, A., Poli, A., Fiume, R., Blalock, W., Matteucci, A., Ramazzotti, G., McCubrey, J. a, Cocco, L., Faenza, I., 2014. PLC-beta 1 regulates the expression of miR-210 during mithramycin-mediated erythroid differentiation in K562 cells. Oncotarget 5, 4222-4231.

Bunnell, B.A., Flaat, M., Gagliardi, C., Patel, B., Ripoll, C., 2008. Adipose-derived stem cells: isolation, expansion and differentiation. Methods 45, 115-120. https://doi. org/10.1016/j.ymeth.2008.03.006.

Chen, Q., Shou, P., Zheng, C., Jiang, M., Cao, G., Yang, Q., Cao, J., Xie, N., Velletri, T., Zhang, X., Xu, C., Zhang, L., Yang, H., Hou, J., Wang, Y., Shi, Y., 2016. Fate decision of mesenchymal stem cells: adipocytes or osteoblasts?. Cell Death Differ. 23, 1128-1139. https://doi.org/10.1038/cdd.2015.168.

Clevers, H., Loh, K.M., Nusse, R., 2014. Stem cell signaling. An integral program for tissue renewal and regeneration: Wnt signaling and stem cell control. Science 346, 1248012. https://doi.org/10.1126/science.1248012.

Cocco, L., Manzoli, L., Faenza, I., Ramazzotti, G., Yang, Y.R., McCubrey, J.A., Suh, P.-G., Follo, M.Y., 2016. Modulation of nuclear PI-PLCbeta1 during cell differentiation. Advances in Biological Regulation https://doi.org/10.1016/j.jbior.2015.10.008.

Deng, Z.-L., Sharff, K.A., Tang, N., Song, W.-X., Luo, J., Luo, X., Chen, J., Bennett, E., Reid, R., Manning, D., Xue, A., Montag, A.G., Luu, H.H., Haydon, R.C., He, T.-C., 2008. Regulation of osteogenic differentiation during skeletal development. Front. Biosci. 13, 2001-2021.

Eswarakumar, V.P., Lax, I., Schlessinger, J., 2005. Cellular signaling by fibroblast growth factor receptors. Cytokine Growth Factor Rev. 16, 139-149. https://doi.org/ 10.1016/j.cytogfr.2005.01.001.

Faenza, I., Bavelloni, A., Fiume, R., Lattanzi, G., Maraldi, N.M., Gilmour, R.S., Martelli, A.M., Suh, P.G., Billi, A.M., Cocco, L., 2003. Up-regulation of nuclear PLCbeta1 in myogenic differentiation. J. Cell. Physiol. 195, 446-452.

Faenza, I., Bavelloni, A., Fiume, R., Santi, P., Martelli, A.M., Maria Billi, A., Lo Vasco, V.R., Manzoli, L., Cocco, L., 2004. Expression of phospholipase C beta family isoenzymes in C2C12 myoblasts during terminal differentiation. J. Cell. Physiol. 200, 291-296.

Faenza, I., Billi, A.M., Follo, M.Y., Fiume, R., Martelli, A.M., Cocco, L., Manzoli, L., 2005. Nuclear phospholipase C signaling through type 1 IGF receptor and its involvement in cell growth and differentiation. Anticancer Res. 25, 2039-2041.

Faenza, I., Blalock, W., Bavelloni, A., Schoser, B., Fiume, R., Pacella, S., Piazzi, M., D'Angelo, A., Cocco, L., 2012. A role for PLC 11 in myotonic dystrophies type 1 and 2. Faseb. J. 26, 3042-3048. https://doi.org/10.1096/fj.11-200337.

Faenza, I., Matteucci, A., Manzoli, L., Billi, A.M., Aluigi, M., Peruzzi, D., Vitale, M., Castorina, S., Suh, P.G., Cocco, L., 2000. A role for nuclear phospholipase Cbeta 1 in cell cycle control. J. Biol. Chem. 275, 30520-30524. https://doi.org/10.1074/jbc.M004630200.

Faenza, I., Ramazzotti, G., Bavelloni, A., Fiume, R., Gaboardi, G.C., Follo, M.Y., Gilmour, R.S., Martelli, A.M., Ravid, K., Cocco, L., 2007. Inositide-dependent phospholipase C signaling mimics insulin in skeletal muscle differentiation by affecting specific regions of the cyclin D3 promoter. Endocrinology 148 , 1108-1117. https:// doi.org/10.1210/en.2006-1003.

Follo, M.Y., Faenza, I., Fiume, R., Ramazzotti, G., McCubrey, J.A., Martelli, A.M., Manzoli, F.A., Cocco, L., 2012a. Revisiting nuclear phospholipase C signalling in MDS. Advances in Biological Regulation https://doi.org/10.1016/j.advenzreg.2011.09.018.

Follo, M.Y., Manzoli, L., Poli, A., McCubrey, J. a, Cocco, L., 2015. PLC and PI3K/Akt/mTOR signalling in disease and cancer. Adv. Biol. Regul. 57C, 10-16. https://doi. org/10.1016/j.jbior.2014.10.004.

Follo, M.Y., Mongiorgi, S., Clissa, C., Paolini, S., Martinelli, G., Martelli, a M., Fioravanti, G., Manzoli, L., Finelli, C., Cocco, L., 2012b. Activation of nuclear inositide signalling pathways during erythropoietin therapy in low-risk MDS patients. Leukemia 26, 2474-2482. https://doi.org/10.1038/leu.2012.133.

Hurley, E.T., Yasui, Y., Gianakos, A.L., Seow, D., Shimozono, Y., Kerkhoffs, G.M.M.J., Kennedy, J.G., 2018. Limited evidence for adipose-derived stem cell therapy on the treatment of osteoarthritis. Knee Surg. Sports Traumatol. Arthrosc. https://doi.org/10.1007/s00167-018-4955-x.

Jackson, R.A., Nurcombe, V., Cool, S.M., 2006. Coordinated fibroblast growth factor and heparan sulfate regulation of osteogenesis. Gene 379, 79-91. https://doi.org/ 10.1016/j.gene.2006.04.028.

James, A.W., Pang, S., Askarinam, A., Corselli, M., Zara, J.N., Goyal, R., Chang, L., Pan, A., Shen, J., Yuan, W., Stoker, D., Zhang, X., Adams, J.S., Ting, K., Soo, C., 2012. Additive effects of sonic hedgehog and Nell-1 signaling in osteogenic versus adipogenic differentiation of human adipose-derived stromal cells. Stem Cell. Dev. 21, 2170-2178. https://doi.org/10.1089/scd.2011.0461.

Kang, Q., Song, W.-X., Luo, Q., Tang, N., Luo, J., Luo, X., Chen, J., Bi, Y., He, B.-C., Park, J.K., Jiang, W., Tang, Y., Huang, J., Su, Y., Zhu, G.-H., He, Y., Yin, H., Hu, Z., Wang, Y., Chen, L., Zuo, G.-W., Pan, X., Shen, J., Vokes, T., Reid, R.R., Haydon, R.C., Luu, H.H., He, T.-C., 2009. A comprehensive analysis of the dual roles of BMPs in regulating adipogenic and osteogenic differentiation of mesenchymal progenitor cells. Stem Cell. Dev. 18, 545-559. https://doi.org/10.1089/scd.2008. 0130 .

Katagiri, T., Yamaguchi, A., Komaki, M., Abe, E., Takahashi, N., Ikeda, T., Rosen, V., Wozney, J.M., Fujisawa-Sehara, A., Suda, T., 1994. Bone morphogenetic protein-2 converts the differentiation pathway of C2C12 myoblasts into the osteoblast lineage. J. Cell Biol. 127, 1755-1766. https://doi.org/10.1083/jcb.127.6.1755.

Kern, S., Eichler, H., Stoeve, J., Klüter, H., Bieback, K., 2006. Comparative analysis of mesenchymal stem cells from bone marrow, umbilical cord blood, or adipose tissue. Stem Cell. 24, 1294-1301. https://doi.org/10.1634/stemcells.2005-0342.

Kim, W.-K., Meliton, V., Bourquard, N., Hahn, T.J., Parhami, F., 2010. Hedgehog signaling and osteogenic differentiation in multipotent bone marrow stromal cells are inhibited by oxidative stress. J. Cell. Biochem. 111, 1199-1209. https://doi.org/10.1002/jcb.22846.

Kratchmarova, I., Blagoev, B., Haack-Sorensen, M., Kassem, M., Mann, M., 2005. Mechanism of divergent growth factor effects in mesenchymal stem cell differentiation. Science 308, 1472-1477. https://doi.org/10.1126/science.1107627.

LI, L., DONG, Q., WANG, Y., FENG, Q., ZHOU, P., OU, X., MENG, Q., HE, T., LUO, J., 2015. Hedgehog signaling is involved in the BMP9-induced osteogenic differentiation of mesenchymal stem cells. Int. J. Mol. Med. 35, 1641-1650. https://doi.org/10.3892/ijmm.2015.2172.

Lukinovic-Skudar, V., Donlagic, L., Banfíc, H., Visnjic, D., Banfic, H., Visnjic, D., 2005. Nuclear phospholipase C-beta1b activation during G2/M and late G1 phase in nocodazole-synchronized HL-60 cells. Biochim. Biophys. Acta 1733, 148-156. https://doi.org/10.1016/j.bbalip.2004.12.009. 
Mongiorgi, S., Follo, M.Y., Yang, Y.R., Ratti, S., Manzoli, L., McCubrey, J.A., Billi, A.M., Suh, P.-G., Cocco, L., 2016. Selective activation of nuclear PI-PLCbeta1 during normal and therapy-related differentiation. Curr. Pharmaceut. Des. 22, 2345-2348.

O'Carroll, S.J., Mitchell, M.D., Faenza, I., Cocco, L., Gilmour, R.S., 2009. Nuclear PLCbeta1 is required for 3T3-L1 adipocyte differentiation and regulates expression of the cyclin D3-cdk4 complex. Cell. Signal. 21, 926-935.

Park, H.W., Kim, Y.C., Yu, B., Moroishi, T., Mo, J.-S., Plouffe, S.W., Meng, Z., Lin, K.C., Yu, F.-X., Alexander, C.M., Wang, C.-Y., Guan, K.-L., 2015. Alternative Wnt signaling activates YAP/TAZ. Cell 162, 780-794. https://doi.org/10.1016/j.cell.2015.07.013.

Piazzi, M., Blalock, W.L., Bavelloni, A., Faenza, I., Raffini, M., Tagliavini, F., Manzoli, L., Cocco, L., 2015. PI-PLC $\beta 1 b$ affects Akt activation, cyclin E expression, and caspase cleavage, promoting cell survival in pro-B-lymphoblastic cells exposed to oxidative stress. Faseb. J. 29, 1383-1394. https://doi.org/10.1096/fj.14-259051.

Pittenger, M.F., Mackay, A.M., Beck, S.C., Jaiswal, R.K., Douglas, R., Mosca, J.D., Moorman, M.A., Simonetti, D.W., Craig, S., Marshak, D.R., 1999. Multilineage potential of adult human mesenchymal stem cells. Science 284, 143-147.

Poli, A., Billi, A.M., Mongiorgi, S., Ratti, S., Mccubrey, J.A., Suh, P.-G., Cocco, L., Ramazzotti, G., 2016. Nuclear phosphatidylinositol signaling: focus on phosphatidylinositol phosphate kinases and phospholipases C. J. Cell. Physiol. 231, https://doi.org/10.1002/jcp.25273.

Poli, A., Faenza, I., Chiarini, F., Matteucci, A., McCubrey, J.A., Cocco, L., 2013. K562 cell proliferation is modulated by PLC $\beta 1$ through a PKC $\alpha-$ mediated pathway. Cell Cycle 12, 1713-1721. https://doi.org/10.4161/cc.24806.

Ramazzotti, G., Bavelloni, A., Blalock, W., Piazzi, M., Cocco, L., Faenza, I., 2016a. BMP-2 induced expression of PLC $\beta 1$ that is a positive regulator of osteoblast differentiation. J. Cell. Physiol. 231, https://doi.org/10.1002/jcp.25107.

Ramazzotti, G., Faenza, I., Fiume, R., Billi, A.M., Manzoli, L., Mongiorgi, S., Ratti, S., McCubrey, J.A., Suh, P.-G., Cocco, L., Follo, M.Y., 2017. PLC- $\beta 1$ and cell differentiation: an insight into myogenesis and osteogenesis. Adv. Biol. Regul. 63, 1-5. https://doi.org/10.1016/j.jbior.2016.10.005.

Ramazzotti, G., Faenza, I., Gaboardi, G.C., Piazzi, M., Bavelloni, A., Fiume, R., Manzoli, L., Martelli, A.M., Cocco, L., 2008. Catalytic activity of nuclear PLC-beta(1) is required for its signalling function during C2C12 differentiation. Cell. Signal. 20, 2013-2021. https://doi.org/10.1016/j.cellsig.2008.07.009.

Ramazzotti, G., Maria Billi, A., Manzoli, L., Mazzetti, C., Ruggeri, A., Erneux, C., Kim, S., Suh, P.-G., Cocco, L., Faenza, I., 2016b. IPMK and $\beta$-catenin mediate PLC- $\beta 1$-dependent signaling in myogenic differentiation. Oncotarget https://doi.org/10.18632/oncotarget.11527.

Ratti, S., Ramazzotti, G., Faenza, I., Fiume, R., Mongiorgi, S., Billi, A.M., McCubrey, J.A., Suh, P.-G., Manzoli, L., Cocco, L., Follo, M.Y., 2018. Nuclear inositide signaling and cell cycle. Advances in Biological Regulation https://doi.org/10.1016/j.jbior.2017.10.008.

Rhee, S.G., 2001. Regulation of phosphoinositide-specific phospholipase C. Annu. Rev. Biochem. 70, $281-312$.

Sancricca, C., Shenaq, D., Huang, J., Zhang, W., Zhang, B.-Q., He, B.-C., Chen, L., Zuo, G.-W., Luo, Q., Shi, Q., Wagner, E.R., Huang, E., Gao, Y., Gao, J.-L., Kim, S.H., Zhou, J.-Z., Bi, Y., Su, Y., Zhu, G., Luo, J., Luo, X., Qin, J., Reid, R.R., Luu, H.H., Haydon, R.C., Deng, Z.-L., He, T.-C., 2010. Mesenchymal stem cells: molecular characteristics and clinical applications. World J. Stem Cell. 2, 67. https://doi.org/10.4252/wjsc.v2.i4.67.

Shi, K., Lu, J., Zhao, Y., Wang, L., Li, J., Qi, B., Li, H., Ma, C., 2013. MicroRNA-214 suppresses osteogenic differentiation of C2C12 myoblast cells by targeting Osterix. Bone 55, 487-494. https://doi.org/10.1016/j.bone.2013.04.002.

Shimizu, T., Tanaka, T., Iso, T., Matsui, H., Ooyama, Y., Kawai-Kowase, K., Arai, M., Kurabayashi, M., 2011. Notch signaling pathway enhances bone morphogenetic protein 2 (BMP2) responsiveness of Msx2 gene to induce osteogenic differentiation and mineralization of vascular smooth muscle cells. J. Biol. Chem. 286, 19138-19148. https://doi.org/10.1074/jbc.M110.175786.

Spinella-Jaegle, S., Rawadi, G., Kawai, S., Gallea, S., Faucheu, C., Mollat, P., Courtois, B., Bergaud, B., Ramez, V., Blanchet, A.M., Adelmant, G., Baron, R., Roman-Roman, S., 2001. Sonic hedgehog increases the commitment of pluripotent mesenchymal cells into the osteoblastic lineage and abolishes adipocytic differentiation. J. Cell Sci. 114, 2085-2094.

Woei Ng, K., Speicher, T., Dombrowski, C., Helledie, T., Haupt, L.M., Nurcombe, V., Cool, S.M., 2007. Osteogenic differentiation of murine embryonic stem cells is mediated by fibroblast growth factor receptors. Stem Cell. Dev. 16, 305-318. https://doi.org/10.1089/scd.2006.0044.

Wu, M., Chen, G., Li, Y.-P., 2016. TGF- $\beta$ and BMP signaling in osteoblast, skeletal development and bone formation, homeostasis and disease. Bone Res 4, 16009. https: //doi.org/10.1038/boneres.2016.9.

Wymann, M.P., Schneiter, R., 2008. Lipid signalling in disease. Nat. Rev. Mol. Cell Biol. 9, 162-176. https://doi.org/10.1038/nrm2335.

Yuan, Z., Li, Q., Luo, S., Liu, Z., Luo, D., Zhang, B., Zhang, D., Rao, P., Xiao, J., 2016. PPAR $\gamma$ and Wnt signaling in adipogenic and osteogenic differentiation of mesenchymal stem cells. Curr. Stem Cell Res. Ther. 11, 216-225.

Zimmerlin, L., Park, T.S., Zambidis, E.T., Donnenberg, V.S., Donnenberg, A.D., 2013. Mesenchymal stem cell secretome and regenerative therapy after cancer. Biochimie 95, 2235-2245. https://doi.org/10.1016/j.biochi.2013.05.010.

Zuk, P.A., Zhu, M., Mizuno, H., Huang, J., Futrell, J.W., Katz, A.J., Benhaim, P., Lorenz, H.P., Hedrick, M.H., 2001. Multilineage cells from human adipose tissue: implications for cell-based therapies. Tissue Eng. 7, 211-228. https://doi.org/10.1089/107632701300062859. 